\title{
Articulaçóes metropolitanas, políticas municipais: desafios e avanços do planejamento territorial na Regiáo Metropolitana de Curitiba (Brasil)
}

Julio Carmo. Universidade Federal de Mato Grosso do Sul, Campo Grande, Brasil. Tomas Moreira. Universidade de São Paulo, São Paulo, Brasil.

RESUmo | Curitiba (Brasil) implantou um processo contínuo de planejamento, com mais de cinco décadas, materializado em uma instituição e planos que lhe moldaram e foram propaganda utilizada por políticos e planejadores como um caso de sucesso. Mas, se Curitiba é apontada como modelo de planejamento, a Região Metropolitana de Curitiba (RMC) não obteve tal reconhecimento, ainda que tenha uma instituição responsável e considerável tempo de planejamento (quarenta anos em 2014) - elementos apontados na literatura como bases do sucesso de Curitiba -, bem como recebido e transferido técnicos para seu equivalente municipal. Dessa forma, tendo como método a historiografia, conclui-se que a região não tirou proveito do diferencial de planejamento e qualidade de vida do polo, pelo contrário, o aprofundamento do processo de planejamento contribuiu para as diferenças sociais, valorizando o solo da capital e restringindo o acesso daqueles que chegaram à cidade atraídos pela cidadania que essa parecia oferecer.

PALAVRAS-CHAVE | áreas metropolitanas, integração regional, ordenamento territorial.

ABSTRACT | For more than five decades, Curitiba (Brazil) has implemented a continuous process of planning, shaped by institutions and plans that were used as "success case propaganda" used by politicians and planners. However, if Curitiba was entitled as a planning model, the Metropolitan Region of Curitiba (MRC) did not obtain such recognition, even though it has been a responsible institution for a considerable amount of time (forty years in 2014) - elements pointed out in the literature as bases of the success of Curitiba - as well as received and transferred technicians to its municipal equivalent. As a result of this analysis, based on an historiographical method, we conclude that the region did not take advantage of the poles' differential of planning and quality of life, on the contrary, the deepening of the planning process contributed to increase social differences, land value in the capital, and in restricting the access of those who arrived to the city attracted by the citizenship that seemed to be offered.

KEYWORDS | metropolitan areas, regional integration, spatial planning. 


\section{Introduçáo}

No desenrolar da história, o urbano esteve sujeito a uma contínua redefinição de formas e conteúdos, resultando em diversas transformaçóes da estrutura interna da cidade. $\mathrm{O}$ aprofundamento dessas dinâmicas nas últimas décadas revelou que a urbanizaçáo constituiu-se em condição geral de um processo no qual o território teve suas funçóes redefinidas, podendo facilitar este processo ou, então, tornar-se um obstáculo à sua realizaçáo. Com o advento de novas estruturas e ideologias que complementam ou superam as anteriores se tornou possível, em cada época, a construção de novos referenciais que alteraram substancialmente sua forma e estrutura, redefinindo suas funçóes e conteúdos.

Partindo da interpretação das complexidades que se sucederam na produção espacial e social das regióes metropolitanas no Capitalismo, delimitou-se pesquisar as relaçóes entre o planejamento urbano e o metropolitano, com especial interesse em uma regiáo metropolitana que tenha como seu núcleo um município que seja reconhecido por autores acadêmicos ou pelo mainstream como modelo de planejamento urbano. Para analisar como essas condiçóes ocorrem na realidade, foi selecionada a cidade no Brasil que desde os anos 1970 tornou-se referência enquanto exemplo de planejamento urbano, Curitiba, e sua Região Metropolitana, localizada no estado do Paraná (figura 1).

O recorte temporal teve como ponto de partida o processo de metropolizaçáo que caracterizou a regiáo após os anos 1990 e o planejamento territorial realizado desde então, importantes no sentido de refletirem o pensamento das instituiçóes, sociedade e responsáveis pelo planejamento na RMC. Busca-se revelar estratégias e personagens que conformaram a atual inserção da região enquanto metrópole secundária ${ }^{1}$ no contexto nacional. Já o ponto final da análise foi a promulgação do Estatuto da Metrópole, pelo Governo Federal, em 2015, que abriu novas expectativas frente à questão metropolitana no Brasil.

O reconhecimento ou críticas ao planejamento urbano de Curitiba são recorrentes na literatura e na produção acadêmica, sendo um dos motivos do aparente sucesso a sequência política à frente do executivo municipal. Por outro lado, são poucas as referências sobre a gestáo e o planejamento metropolitano que situem seus significados e papéis no processo pelo qual passou a RMC desde sua institucionalização. Observe-se que a produção de análises sobre o planejamento urbano de Curitiba e o IPPUC, contrasta com a atenção dispensada ao planejamento metropolitano da RMC e à ação da COMEC (Coordenaçáo da Região Metropolitana de Curitiba) na escala metropolitana.

Dessa forma, a hipótese que se colocou frente ao tema proposto e que é o fio condutor deste texto é que, historicamente, no quadro institucional construído, as cidades consideradas centrais na rede urbana não foram capazes de assumir sua dimensão metropolitana. No caso de Curitiba, essa condição aliou-se a um ininterrupto processo de planejamento e divulgação desse como um caso de sucesso, após a

Para Firkowski e Casares (2014), metrópoles secundárias (ou regionais) seriam escalas referenciais de análise com dinâmicas específicas, não se confundindo com as metrópoles globais. 
década de 1960, realizado em nível municipal, mas não correspondente para a escala metropolitana, ainda que os cenários, em geral, sejam similares. Assim, o objetivo geral é compreender - em um contexto onde o planejamento do município polo da regiấo metropolitana é ou foi tido como modelo -, as convergências, divergências e descompassos entre o planejamento do núcleo e o metropolitano. São exploradas as relaçóes entre ambas as escalas de planejamento, expondo a tensão existente entre as açôes formais (dispositivos legais) e as materiais (implantação de açôes concretas, com impactos/resultados, esperados ou náo) no campo do planejamento, contemplando a força da variável política, da autonomia político-administrativa e das diferentes capacidades técnicas instaladas entre as escalas, discutindo as relaçóes com o município polo e o alcance de programas, projetos e planos. Portanto, esta pesquisa resulta da análise das relaçóes entre o planejamento de Curitiba e o elaborado para a região metropolitana a partir dessas condiçóes.

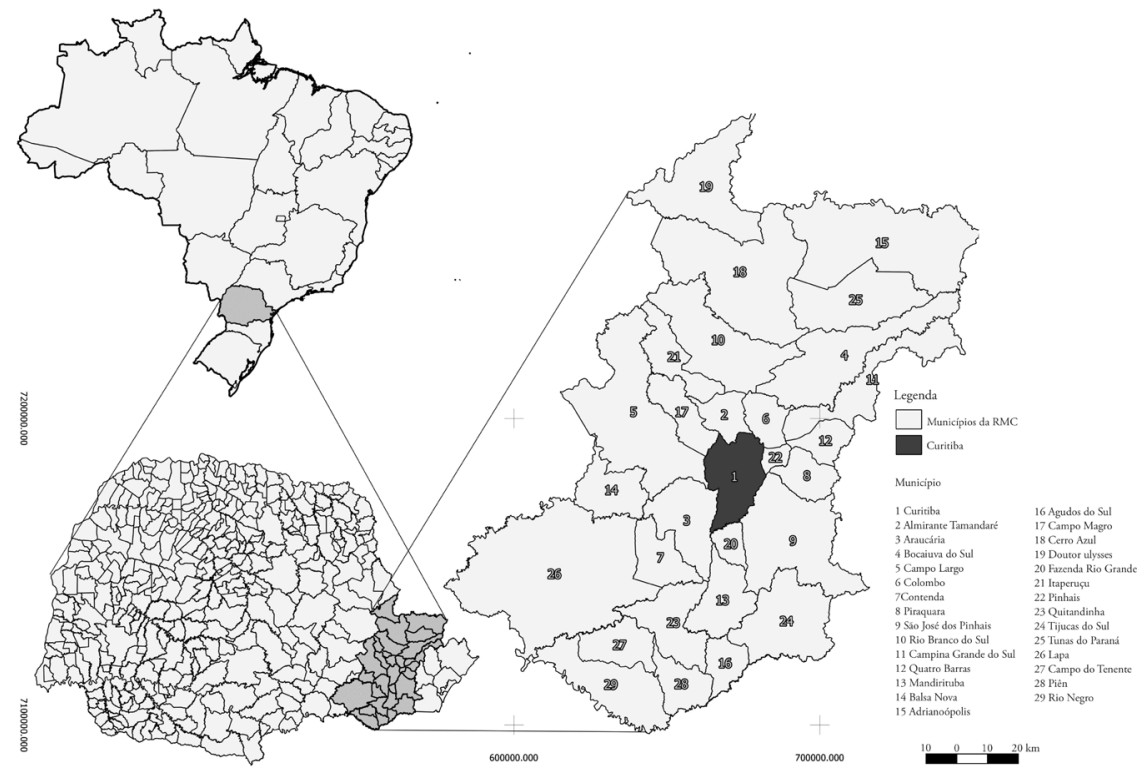

\section{FIGURA I | Localização da Regiáo Metropolitana de Curitiba (RMC) em relação} ao Paraná e Brasil

FONTE: CARMO, 2018

Esta pesquisa qualitativa, teve como método a historiografia. O levantamento bibliográfico e de documentação foi realizado junto aos órgãos municipais e estaduais de pesquisa e planejamento urbano, bem como em bancos digitais de teses e dissertaçóes, de forma a contribuir na análise e permitir referenciar no tempo e espaço os avanços e desafios identificados.

A análise das informaçóes foi realizada a partir da bibliografia sobre o tema, traçando paralelos que identificassem a diferenciação e as relaçóes entre o planejamento no município de Curitiba, nos demais municípios e o realizado para o espaço metropolitano. 
Com base na bibliografia colocada e nas constataçóes apresentadas, a ligação teórica que se estabeleceu foi que a região metropolitana, por ser um produto social e histórico, só pode ser compreendida a partir de sua relação com as determinaçóes mais gerais que regem e articulam os municípios metropolitanos e seus modos e processos de produçáo, reprodução e transformação econômica e social. Articulaçáo essa que não é linear, pois, embora produto do processo produtivo, as regióes metropolitanas constituem-se em condição geral desse mesmo processo, razão pela qual poderiam vir a facilitá-lo ou, então, tornar-se um obstáculo à sua realizaçáo, conforme observa Harvey (2006).

\section{Articulaçóes metropolitanas, políticas municipais}

Em Curitiba, ao se intensificar a expansão sobre os municípios vizinhos à metrópole, em função da proximidade física e das facilidades de acesso à terra e aos meios de transporte de passageiros, levou-se à periferização comum às demais RMs do país, ainda que no caso da RMC os cidadáos metropolitanos fossem iludidos pelo "acesso à economia e à cidadania curitibanas" (COMEC, 2006, p. 17).

Essa intensificação da expansão consolidou o anel urbano no entorno de Curitiba, não fortalecendo os municípios próximos, mas gerando dissociação entre o local de moradia e aquele de consumo e trabalho, restringindo a cooperação na alocação de funçóes urbanas, além de manter municípios mais distantes em posiçóes de suporte às atividades rurais, pouco integrados à metrópole (Instituto Paranaense de Desenvolvimento Econômico e Social [IPARDes], 2010). Tendendo a metrópole a concentrar (renda, população, indústrias de alta tecnologia e trabalho qualificado) e centralizar os mecanismos de administração e controle do capital, com vistas a reafirmar e renovar sua centralidade, Curitiba passou a constituir um novo patamar da urbanização, onde o processo espacial da metropolização passou a privilegiar determinadas funçóes urbanas, transformando o sistema produtivo, organizando e recompondo territórios com dimensóes urbanas cada vez maiores.

Sua história atribuiu novos valores de uso a uma metrópole fragmentada, enquanto base para a nova estratégia de desenvolvimento. Decorrente dessa fragmentação, poucos municípios foram inseridos no processo de mudança econômica. Com exceção de Curitiba, Araucária e São José dos Pinhais, e em menor escala, Campo Largo, os demais municípios da região (25) prosseguem sendo eminentemente rurais ou cidades-dormitório. O mercado de trabalho se tornou então o fator que unifica todo o conjunto; persistem e se aprofundam, as diferenças sociais entre os municípios, permanecendo à margem aqueles que não foram selecionados ou náo se adequaram ao processo (Nojima, Moura, \& Silva, 2009, p. 180).

Ou seja, a seletividade do capital ampliou e aprofundou as diferenças intrarregionais, originando novas espacialidades ao mesmo tempo em que excluiu parcela significativa do território e da populaçáo das vantagens e transformaçóes decorrentes da reestruturação ocorrida. Portanto, o histórico de planejamento do espaço intraurbano não se efetivou em âmbito regional. Essa realidade fez com que a nova dimensão que Curitiba atingiu na década de 1990 acabasse por não utilizar o diferencial de planejamento e qualidade de vida que o polo oferecia, pelo contrário, 
o aprofundamento do processo de planejamento contribuiu para o aumento das diferenças sociais, valorizando o solo da capital e restringindo o acesso daqueles que chegaram à cidade atraídos pela cidadania que a cidade parecia oferecer. Ao analisar o processo de planejamento de Curitiba, seria possível afirmar de forma simplista que se o mesmo processo tivesse ocorrido na região, muitos problemas teriam sido resolvidos. Essa afirmativa não poderia ser real, uma vez que o aparente sucesso do planejamento implantado na área central e prioritariamente adensável (os eixos estruturais) prescindiam da necessidade de espaços que abrigassem as populaçóes expelidas dos espaços planejados pela falta de acesso econômico. Se tal modelo de planejamento tivesse tido sucesso em toda a RMC, os menos favorecidos estariam - possivelmente - ainda mais distantes da dinâmica metropolitana. Portanto os espaços ilegais e os não planejados rapidamente deteriorados, perderam valor, como parte da estratégia de assentamento desta populaçáo mais pobre.

Nesse sentido, a ação do Estado e do mercado imobiliário são visíveis quando se analisa pela perspectiva social as açóes implantadas em Curitiba. Assim, menos que um modelo, Curitiba deve ser vista como uma experiência, um método relativamente bem-sucedido, mas não possível de ser replicado, mesmo em seu âmbito regional, como se pressupóe ser possível quando se pensa em modelos. Obviamente, em primeiro lugar, essa transposição náo seria possível devido ao fato de se tratar de uma regiáo metropolitana e não de um único município. Entretanto, se observa que nos campos em que houve interesse do município polo e necessidade, tais como transportes e proteção dos mananciais, as açóes implantadas foram mais efetivas, sobretudo se comparadas à realidade de outras RMs brasileiras.

A criação de uma imagem hegemônica da cidade permitiu que ao receber de forma acrítica as decisóes sobre a mesma, fossem desencorajadas a dissidência, o contraponto ou a realização de imagens alternativas. Em Curitiba, se utilizaram com habilidade de slogans e apelando aos sentimentos do cidadâo para conformar tal imagem tanto quanto utopia como realidade. Com a mensagem que os problemas se resolviam em nível institucional, não havia necessidade de participação cidadã na melhoria de vida da cidade, uma vez que tudo estava feito e funcionando. Com os problemas aparentemente resolvidos, adotaram uma postura passiva, construindo um orgulho cidadáo acrítico e socialmente irresponsável, que contribui para a manutenção do status quo e da estrutura de poder das classes dominantes. Nos anos oitenta houve um breve período em que diminuiu o ritmo de açóes institucionais para se integrar a metrópole. Com redução nos investimentos públicos federais e estaduais, o fator que havia impulsionado a gestão intermunicipal porquanto exigia, de forma negociada entre as comunidades, o compartilhamento territorial dessas obras e açóes. De outro lado, Curitiba elaborava um novo Plano Diretor local que poderia influir estruturalmente nas cidades vizinhas.

Como consequência, na transição para os anos noventa, a Coordenação da Região Metropolitana de Curitiba (сомеc), exerceu pulverizadas funçóes de assessoria municipal com soluçôes genéricas e financiamentos localizados, para cada comunidade municipal. Enquanto isso, o poder executivo de Curitiba declarou, durante debates legislativos sobre o Estatuto da Cidade em 1992, que os impasses urbanos na capital só teriam solução em projetos de âmbito regional, que estabelecessem 
açóes compartilhadas com os demais municípios da região. Além das políticas de abastecimento de água e infraestrutura, começaram então a firmar convênios bilaterais com as cidades vizinhas. Na segunda metade dos anos noventa, a capital e seu planejamento permanente, situado no Instituto de Pesquisa e Planejamento urbano de Curitiba (IPPUC), voltaram a contribuir tecnicamente nos projetos metropolitanos. A ênfase era orientar os investimentos federais e estaduais na região, especialmente o contorno rodoviário a Leste e os programas com o Banco Interamericano de Desenvolvimento (BID) e o Programa de Saneamento Ambiental da RMC (PROSAM). Pretendiam acomodar a indústria automotiva e outros complexos comerciais e industriais, bem como questóes de emergência, sobretudo nas políticas para o transporte microrregional e o meio-ambiente. Da preocupação com uso e ocupação do solo, como habitação e localização industrial, se passou a transporte e meio-ambiente, enquanto a geografia histórica da expansão mundial capitalista (desigual e combinada) servia como pano de fundo.

Nessa década, de forma a garantir seus interesses, após não assumir o planejamento na prática na escala metropolitana, ainda que influenciando os vizinhos com o IPpuc, a prefeitura de Curitiba utilizaria a Urbanização de Curitiba SA (URbs) como instrumento para conseguir tal feito. A partir da passagem do transporte coletivo para a gestão desta ${ }^{2}$, todas as articulaçôes políticas e de gestão passaram por Curitiba, sendo poucas realizadas entre os municípios, até seu desmembramento em 2015. Persiste, a escassez de ligaçóes diretas entre os municípios, fazendo com que a maior parte dos deslocamentos ainda inclua passar por Curitiba.

A desintegração se deveu à visão da URBs, que insistia que os passageiros metropolitanos que utilizavam o sistema integrado aumentavam o valor da tarifa técnica, a ser pago pelo governo do Estado. Contudo, esse não pretendia assumir mais despesas financeiras. De acordo com Klink (2010), "a postura estritamente financeira da URBS é incompatível com o papel estratégico da política de transporte público e mobilidade como instrumento de indução para o desenvolvimento metropolitano sustentável" (p. 34), confirmando que "o processo intenso de metropolização, agravado pela proliferação de conflitos entre agentes e escalas, também desafiou a capacidade de exportar o modelo curitibano de transporte e mobilidade para a região metropolitana como um todo" (p. 36). Confirma tal fato, por exemplo, o sistema BRT, implantado em Curitiba nos anos 1970, estar presente em $2016 \mathrm{em}$ mais de duzentas cidades no mundo e 34 no Brasil, sequer atingir os municípios mais próximos, com exceção de Pinhais.

Além dos transportes, decorrentes dos processos de consolidação da metropolização, populacional e econômica, as reestruturaçóes produtivas características dos anos 1970 e 1990, sobretudo as questóes de uso e ocupação do solo, levaram à consolidação do Leste da região. Essa estratégia estava integrada à Política de Desenvolvimento Urbano do Paraná, imposta a partir de 1972, que deslocou o eixo econômico preferencial da metrópole linear que se configurava no Norte do estado

2 Em 2015, quando dois grupos adversários estavam à frente da Prefeitura de Curitiba (Gustavo Fruet - PDT) e do estado do Paraná (Carlos Alberto Richa - PSDB), houve a desagregação do sistema de transportes. Com o retorno do aliado do governador, Rafael Greca (PMN), em 2017, foi reiniciado o processo para integrar os dois sistemas. 
- entre Maringá, Apucarana e Londrina - para o novo eixo concentrador - baseado na região de Curitiba. O foco na produção agrícola foi substituído pelas políticas de industrialização, sobretudo a partir dos anos 1980, decorrente da consolidação da Cidade Industrial de Curitiba (Cıc) além da descentralização industrial a partir de São Paulo. A instalação da refinaria da Petrobrás, no município de Araucária, e a criação do centro industrial deste município (CIAR), também na década de 1970, representam o ponto inicial de transformação e reestruturação produtiva não apenas da RMC, mas do estado do Paraná de forma geral. Como afirma Moura (2009:

A metrópole linear em fase de constituição no Norte Central do estado ofusca-se com o reforço econômico e institucional obtido por Curitiba, ainda em processo inicial de metropolização, mas já beneficiada pelo peso dos investimentos públicos e privados, adequando e modernizando sua infraestrutura urbana. Obteve ainda respaldo formal, com a institucionalizaçáo da Região Metropolitana de Curitiba, por lei federal, que lhe garantiu, por determinado período, inversóes complementares em infraestrutura e serviços de interesse metropolitano. (Moura, 2009, p. 134)

A política industrializante imposta pelo grupo do governador Jaime Lerner, à frente do executivo estadual, após consolidar o eixo industrial Curitiba/Araucária na década de 1970, transformou São José dos Pinhais, a Leste, na segunda principal centralidade da região, terceiro em produção e arrecadação industrial na década de 1990, saltando para segundo na última década, atingindo quase 300 mil habitantes e tornando-se o sexto município mais populoso do estado (Instituto Brasileiro de Geografia e Estatística [IBGE], 2010). Arazaki (2007) defende que ao longo de trinta anos (entre a década de 1970 e os anos 2000), o desenvolvimento econômico na RMC não foi homogêneo, gerando um anel de dependência em relação à Curitiba, ainda que nos últimos anos, esta nova centralidade (São José dos Pinhais) esteja despontando no cenário metropolitano. Evidência descrita em uma série de estudos (Godoy, 2012; ibge, 2014; IPARdes, 2004; Moura, 2009; Pilotto, 2010).

Por outro lado, a expansão da RMC não se baseou apenas nos clássicos motivos apontados em vantagens econômicas, mas também esteve ligado ao "modelo" de Curitiba, que emprestava "prestígio político, principalmente junto aos eleitores. Era frequente um habitante de Colombo, por exemplo, se dizer morador de Curitiba, pois então ele achava que era 'tudo a mesma coisa'" (Castro Neto em entrevista para o autor, 2015). Isso acabava por ser um benefício duplo, para o estado, que consolidava a imagem de sua capital, e para o município incluído, que passava a ter a possibilidade de ser "confundido" com Curitiba. Contudo, nos últimos anos, sobretudo em Sáo José dos Pinhais - centralidade secundária -, teve início um movimento de não se utilizar mais o nome de Curitiba, por exemplo, para se referir ao aeroporto internacional, que passaria a ser denominado "Aeroporto Internacional de São José dos Pinhais", se desvinculando do polo e fortalecendo aspectos locais ${ }^{3}$. De acordo com os técnicos entrevistados, inclusive, há prefeitos, como o do município de Rio Negro, que pretendem sair da região, ao perceberem que as expectativas da inclusão na região metropolitana (incentivada por parlamentares 
estaduais) não se tornaram reais. Nesse sentido, Rolnik (2006, p. 203) define como "política de salve-se quem puder", a que pautou as municipalidades para atraçáo de investimentos e investidores no país durante os anos 1990, fomentando a guerra fiscal entre cidades, e inviabilizando projetos regionais e de cooperaçáo, levando as mesmas abrirem mão de receitas, e que, aliada à descentralização, acabou enfraquecendo os poderes locais e aumentou o poder das corporaçóes. Ao contrário, na RMC, o protagonismo adotado pelo estado nas gestôes Lerner persistiu a manter a regiáo enquanto extensáo ou base da economia de Curitiba, se desenvolvendo de forma dependente das ações que eram definidas pela capital, sobretudo de localização e uso do solo.

Recorrente na literatura, a impressão da polarização entre um centro rico (Curitiba) e a periferia pobre (restante da RMC) seria, portanto, redutora, pois a periferia também existe dentro dos limites político-administrativos de Curitiba e sistematicamente aparecem locais valorizados nos demais municípios. Aceitar tal impressão implicaria em reconhecer uma parte da cidade-modelo, como um todo, o que náo encontraria respaldo na realidade. Esse quadro corrobora o apontado por Lencioni (2011) e Ojima (2007), para quem

... considerar os municípios periféricos meramente como 'região periférica', lhes confere uma importância indevida na organização do espaço metropolitano, visto que a metrópole brasileira é, nos dias de hoje, a soma de valores que extrapolam os limites físicos, econômicos e sociais do município-sede. Enfim, é preciso entender a metrópole enquanto unidade analítica que possui sim uma localidade central ou polarizadora, mas que náo sobrevive sem se considerar a sua conjuntura regional.

(Ojima, 2007, p. 48)

Ainda que a teoria centro-periferia seja redutora, há coerências com o pensamento cepalino, quando se observa que os motivos que levaram a experiência de Curitiba a ser considerada de êxito pode ser ter trilhado um caminho próprio dentro do planejamento realizado nos países subdesenvolvidos, ao não copiar ou emular de forma acrítica as práticas e teorias postas pelos países desenvolvidos. Contudo, com o tempo, essa diferenciação em termos regionais não se propagou, levando o município a ser durante um período uma ilha de prosperidade cercada por municípios atrasados economicamente, se transformando em um conjunto de ilhas de prosperidade que gravitam em torno do polo nos últimos anos. No início do seu processo era a periferia do capitalismo em relação ao país. Quando se volta para si em um processo autônomo de planejamento, passou a conduzir o desenvolvimento capitalista da regiấo. Não foi etapista, mas um caminho alternativo. Ao contrário, em nenhum momento a COMEC vislumbrou trilhar um caminho autônomo de desenvolvimento, compreendendo que a escala metropolitana precisaria ter um tratamento diferenciado caso quisesse galgar a qualidade que se falava sobre Curitiba.

Apesar disso, o estado estabeleceu um crescente esforço para elaborar com seus próprios técnicos os planos e projetos regionais, sobretudo a partir de 1978, quando se concluiu o primeiro Plano de Desenvolvimento Integrado (PDI) e depois dotando todas as comunidades vizinhas à Curitiba de um Plano de Uso e Ocupação do Solo, cujo formato se articula às políticas urbanas utilizadas na capital. Gradualmente 
a Coordenação da Região Metropolitana de Curitiba (comec), como entidade consolidada da administração estadual, adquiriu a estatura de Secretaria de Estado, revogando o vínculo institucional com o planejamento da capital. A continuidade do processo de planejamento - consequentemente de seus planos - é um indicativo de colaboração metropolitana. Nesse sentido, de acordo com Moura e Rodrigues (2009), como aconteceu em outras metrópoles, o impacto do incremento de população e consequente intensificação do uso do solo em Curitiba, foi concomitante ao seu processo de planejamento. Tal processo, ao reforçar uma imagem positiva da cidade, permitiu que se valorizasse seu espaço urbano, elevando o valor das moradias, o custo de melhorias, de tributos, tornando seletiva a ocupação e transferindo os mais pobres para suas periferias ou para os municípios vizinhos, induzindo a habitação em áreas ilegais, em assentamentos precários, terrenos frágeis, zonas de expansão periférica, sem infraestrutura e exluída dos sistemas financeiros oficiais, onde a terra era mais barata. Ao mesmo tempo, sobretudo a partir de 1992, com a RIT, permitia o acesso à capital por meio de transporte público, facilitando o deslocamento casa-trabalho, e de forma fictícia fortalecia um sentimento de pertencimento à metrópole. $\mathrm{O}$ binômio, apontado por autores como principais avanços de Curitiba - uso do solo e transportes - novamente agia em parceria.

Isso ocorre devido ao fato que, como alertava Ferrari (1979) nos anos 1970, os polos de desenvolvimento deverem ser planejados com o fim de desenvolver a regiấo homogênea a qual pertencem, contudo, a experiência já mostrava que os efeitos positivos da polarização não acontecem onde não há uma suficiente rede de comunicaçóes e transportes. Reforçavam-se efeitos centrípetos ou regressivos, os transformando em polos de subdesenvolvimento, ampliando consideravelmente as diferenças entre centro e os demais municípios. Portanto, mesmo com todo knowhow que possuíam não seriam capazes de fazer o planejamento metropolitano acontecer.

\section{Avanços}

No caso da RMC, decorrente dessas disparidades, se convencionou que a crítica relativa à COMEC se ateria a pouca efetividade do órgáo, como se tivesse sido frágil na articulação metropolitana. Klink, por exemplo, afirma que

Não obstante, enquanto a estrutura organizacional e o modo de operação da COMEC não mudaram significativamente desde os anos 70 , no quadro atual a instituição depara-se com um ambiente geopolítico e institucional mais complexo e altamente contestado, marca geral das áreas metropolitanas brasileiras. (...) a instituição não cumpriu seu papel de "articuladora profissional", no sentido de mediar e negociar uma série de bens públicos que transbordassem para além do território municipal.

$\mathrm{Na}$ prática, os agentes locais consideram a COMEC como um anacronismo, que efetivamente mostrou-se incapaz de se transformar em sujeito e protagonista para o planejamento e gestáo da área metropolitana. (Klink, 2010, p. 26)

Entretanto, o fato é que, apesar de toda a crise financeira a partir dos anos 1980, depois substituída pelo neolocalismo pós-1988, o órgão metropolitano se manteve 
ativo, ainda que sistematicamente atacado. Quanto à pouca efetividade dos planos, o mesmo se observa para o modelo tido de Curitiba. Seus planos foram pouco efetivos, o reconhecimento veio pelas açóes implantadas pelo órgáo de planejamento, que como demonstrou Faraco (2002), não constavam no plano diretor. Por exemplo, a insistência de alguns autores em expressar contrariedade quando destacam que a expansão urbana não se deu sobre a região prevista nos planos para crescimento. Se questiona como podem autores dos planos e outros que analisaram a dinâmica de Curitiba prosseguir insistindo em que o desenvolvimento se desse nessa direção (Oeste), onde o terreno sempre se colocou como um impedimento, que viria a ser consolidado com a criação do Parque e da represa do Rio Passaúna, sepultando as chances de conurbação entre os municípios. De acordo com os técnicos da comec entrevistados, existia uma macrodiretriz para que isso acontecesse, uma vez que náo havia conhecimento aprofundado da regiáo. Por outro lado, a intervenção do governo autoritário sobre o território se manifestou na ação do Departamento Nacional de Obras de Saneamento (DNos) que, sem consulta aos municípios, decidiu pela implantação da represa do Passaúna naquele local.

Nesse sentido, assim como o Plano Diretor de Curitiba náo foi seguido à risca e se adaptou aos distintos momentos, mesmo sendo lei, o que poderia se esperar dos planos metropolitanos que jamais chegaram a tal nível de institucionalização. Obviamente o que chegou em 2015 tendo articulaçáo foram muito mais setoriais, ainda que buscassem se amparar nos PDI (às vezes nem isso). Apesar disso, a mesma sorte de reconhecimento do processo do IPPUC em Curitiba náo obteve a comec, ainda que planos da magnitude do PROSAM tenham ampliado os números sobre abastecimento da água e esgotamento sanitário na RMC. Ou ainda, como no caso dos transportes quando da sua desintegração, que, ao contrário do órgão municipal, a comec passou incólume por greves ou protestos de movimentos sociais, ainda que tomando medidas impopulares, como o degrau tarifário ${ }^{4}$. Tais críticas na academia, principalmente, fazem, portanto, coro às tentativas de desmonte do órgáo, sobretudo por políticos. Atualmente com oito funcionários, é difícil vislumbrar um futuro promissor, de fato. Quando Akel (2015) reassumiu a direção do órgão, havia três anos que os Conselhos não se reuniam. A ampliação territorial havia "esgarçado" o território metropolitano, sendo necessário reconstruir a capacidade de resposta da comec. Os municípios não recorriam mais ao órgão, deixando um passivo de atendimento social para as comunidades, que precisou ser reconstruído. Buscou mais sete funcionários em outros órgãos para contribuir com as atividades, que passaram a ser selecionadas, uma vez que pelo menos os municípios do Núcleo Urbano Central (Nuc, figura 2) em geral já possuem capacidade para realizarem algumas funçóes.

Por fim, acompanhando o movimento observado no país em geral, houveram melhorias nos indicadores sociais e econômicos. De acordo com Programa das Naçôes Unidas para o Desenvolvimento (PNUD) (2013), 0,68\% da populaçáo da RMC era considerada extremamente pobre e $2,62 \%$ pobre em 2010 , enquanto em 2000 esses números eram de 4,78\% e 13,79\% respectivamente. A desigualdade 
social, entretanto, se elevou, passando o índice de Gini que de 0,45 para 0,55, enquanto a esperança de vida ao nascer cresceu 3,6 anos na década, passando de 72,6 anos, em 2000, para 76,2 anos, em 2010. Entre as economias do estado em 2013, quatro das dez maiores estavam na RMc: Curitiba, São José dos Pinhais, Araucária e Pinhais, sendo as duas primeiras as maiores do Paraná. A importância de Curitiba e da RMC permanecem, sobretudo na economia e em termos populacionais, quando se observa que, de acordo com o IBGE (2016), atualmente o Paraná possui 11.163 .018 habitantes, dos quais a RMC conta com 3.502 .790 (32\% do total do estado), sendo 1.892 .442 no polo ( $17 \%$ do estado e $54 \%$ da RMC).

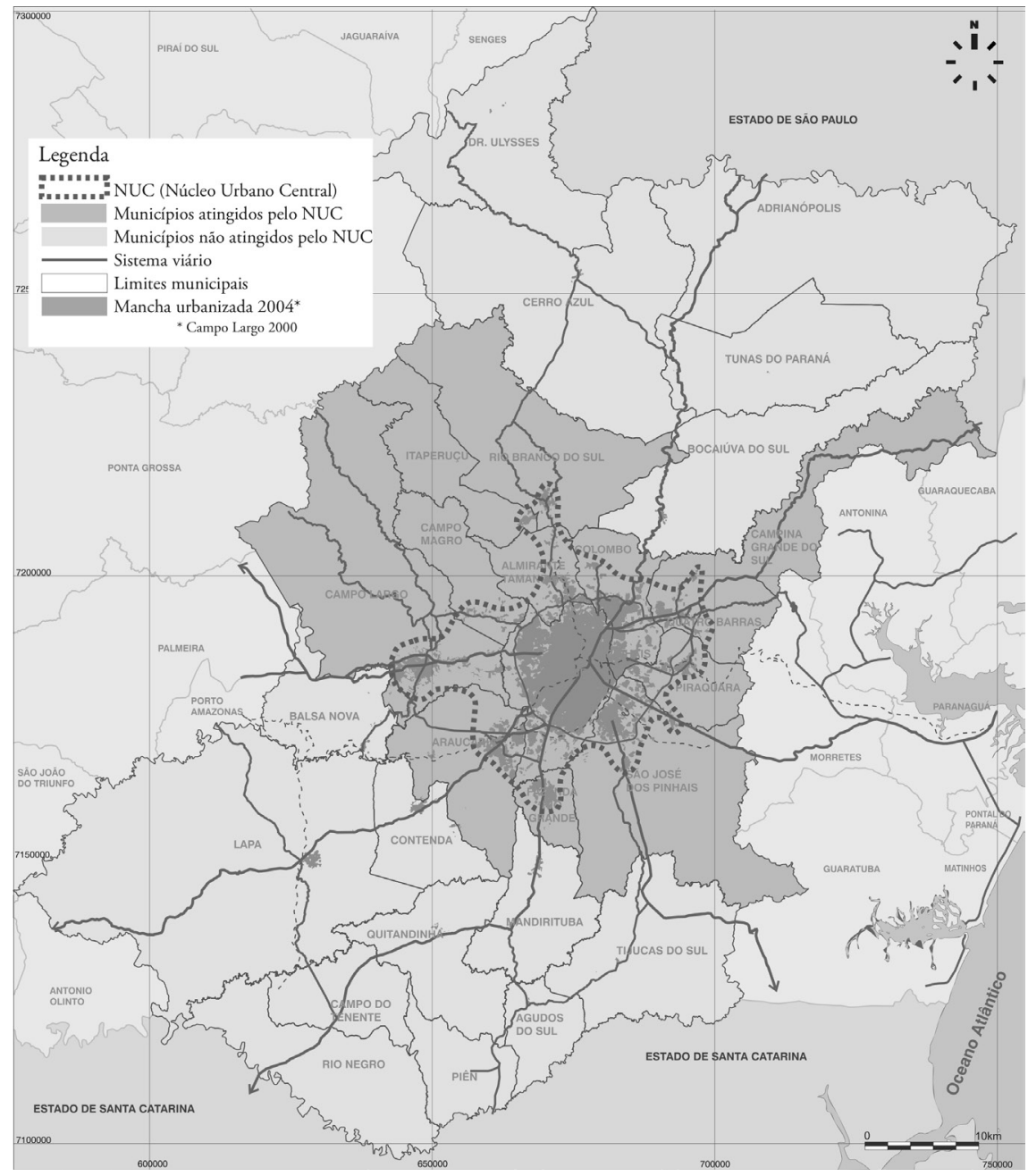

FIgURA 2 Núcleo Urbano Central da RMC (NUC)

FONTE: COMEC, 20I7. ADAPTADO PELOS AUTORES 


\section{Desafios}

Aperfeiçoando esses avanços, no caso da RMC, parece que algumas modificaçôes seriam pertinentes para melhorar a efetividade que a gestão metropolitana tem tido. Em primeiro lugar, faz-se necessário admitir que apenas os municípios integrantes do NUC fazem parte da regiáo metropolitana, o restante não. Até a representação se distingue em duas camadas, uma que é a RM e outra que náo é, a territorial e a institucional, um amalgama de duas dimensóes, que revelam os vários metropolitanos, incluindo aqueles que não o são.

A alteração de 29 para quinze municípios representaria diminuição significativa da burocracia, assimetrias e divergências políticas, restringindo a área de atuação da COMEC, territorialmente, o que na prática já acontece, uma vez que aqueles que estão além do Nuc pouco ou nada aparecem nos relatórios de açóes realizadas pelo órgão. Além das limitaçóes técnicas, isso se deve pela distância e pouca integração à dinâmica metropolitana. Para ilustrar, a sede de Doutor Ulysses, encontra-se a 170 km de distância da capital, Adrianópolis 133 e Rio Negro 115. Em termos comparativos, a principal região metropolitana no Brasil, a de São Paulo (RMSP), o município mais distante está localizado a $101 \mathrm{~km}$ do polo (Salesópolis). A amplitude territorial da RMC levou ainda à criação de paradoxos, como o fato que ela tenha praticamente se tornado uma RIDE, uma vez que os municípios de Rio Negro (PR) e Mafra (SC) são conurbados e isso acaba por enfraquecer ainda mais as articulaçóes do primeiro com outros municípios da RMC. Além disso, a redefinição da regiáo deveria acontecer de forma voluntária e não compulsória (ainda que pareça utópico), permitindo que os interesses legítimos sejam perseguidos. Esta seria uma alternativa importante também para a criação de institucionalização metropolitana, onde a tensão entre os interesses dos municípios está quase sempre presente.

Segundo, a necessidade de se transformar projetos aleatórios e setorizados em políticas públicas compreensivas e articuladas, tal como realizado na área de saneamento durante os anos 1990, promovendo o desenvolvimento local, não apenas crescimento econômico setorial, sendo que o modelo utilizado para os transportes, por exemplo, com açóes a partir de um órgão municipal não parece ser o mais adequado.

Terceiro, a implantação de fato de um Fundo de Desenvolvimento, com participação paritária dos municípios, inclusive prevendo compensaçóes para aqueles que possuem restriçóes ambientais devido à demandas de toda a regiâo, de forma a ativar a economia regional da qual todos participam enquanto integrantes de suas cadeias (retrospectivas e prospectivas) de produção, de forma a corrigir desequilíbrios decorrentes da especialização de funçóes. Para fazer parte da RM o município deveria aceitar participar do fundo que mantenha os investimentos e a própria agência metropolitana e abrir mão do planejamento dos serviços considerados comuns em prol da entidade metropolitana. Uma entidade planejadora e executiva, cujos projetos conjuntos sáo financiados com contribuiçóes dos municípios constituintes, proporcional à utilização dos serviços.

Quarto, o fortalecimento de agências, fóruns, consórcios, cooperativas, como os existentes de Saúde e de Resíduos Sólidos, enquanto instrumentos acessórios de gestáo, náo fechados em si e sem a obrigatoriedade que todos os municípios participem. Poderiam ser setorizados, tal qual a Secretaria Estadual de Educação 
do Paraná o faz, em Área Metropolitana Norte e Área Metropolitana Sul, ou como a emplasa (Empresa Paulista de Planejamento Metropolitano s.A.) o faz para a RMSP, subdividida em seis áreas, por exemplo. Poderiam iniciar com a discussão de arranjos informais, realizados para projetos específicos, para posteriormente elaborar uma estrutura institucional e as consequentes políticas públicas, facilitando a ação do estado de planejar o desenvolvimento destas, coordenar as açóes, coagir e constranger os interesses especulativos e patrimonialistas (Brandão, Costa, \& Alves, 2004), criando as condiçóes para que se construam forças transformadoras produtivas, sociais e políticas.

As municipalidades participantes poderiam se agregar voluntariamente e temporariamente, atribuindo determinados poderes para o órgão metropolitano que então os exerceria. A administração comum seria composta por representantes dos municípios participantes, com uma legislação flexível ao número de funções que deve ser confiado ao órgão e ao número de municípios que devem fazer parte, podendo haver exceçôes, com o estabelecimento de certas condiçôes específicas para a formação de arranjos, que embora pareçam frágeis, defenderiam interesses legítimos, possibilitando propostas de políticas, e evoluindo para estruturas formais (Brandão, 2008). A própria filosofia do IPPUC de ser uma entidade acima do prefeito, portanto não vulnerável a flutuaçóes políticas (isso é vendido como ponto positivo, mas se esquece que de fato ele foi mais assertivo nos períodos sem mudanças políticas, quando esteve no poder o grupo que o instituiu) deveria ser usada na concepção do novo arranjo metropolitano. Entretanto, seria de difícil execuçáo, pela miscelânea de representaçóes políticas que compóem as RMs.

Por fim, a participação e o controle social. Não nas formas de audiências como as que têm sido realizadas, onde os problemas apresentados (sobretudo por leigos) se circunscrevem geralmente a questóes pontuais e sem conhecimento dos processos gerais. É necessário haver memória do processo de planejamento metropolitano, bem como divulgação desse para a sociedade, uma vez que não há como esperar que esta seja participativa se não tiver conhecimento sobre o que ocorre e as possíveis resoluções de problemas. Seminários, que não reúnam apenas técnicos, podem ser uma forma de divulgação, bem como campanhas publicitárias, material didático, entre outros.

O método empregado por Curitiba, durante muitos anos se utilizou da distribuição de material didático (denominado Liçôes Curitibanas), que ainda que seja passível de críticas, foi efetivo em divulgar durante os anos 1990 as açóes que aconteciam na cidade. Ainda assim, em 1965 e 1999 durante as discussóes sobre o planejamento de Curitiba, de acordo com Moura (2014) houveram "apresentaçóes para segmentos parceiros ou para a comunidade despreparada para compreender, absorver e discutir as ideias propostas" (s. p.). Uma vez que, como na frase atribuída ao filósofo grego Sócrates, "as cidades não precisam ser governadas, precisam ser educadas", deve se pensar, portanto, de forma a combater a ideia de favores, lealdades políticas ou clientelismo, bem como de doutrinação e adesão acrítica ao proposto. $\mathrm{O}$ processo decisório precisa se assentar do cidadão até às instituiçôes, conscientizando sobre os problemas, suas causas e soluçóes adequadas às especificidades, bem como formas de mobilização, garantindo ao planejamento maior representatividade, 
distribuição objetiva de recursos e as prioridades em nível regional, estabelecendo políticas, diretrizes, estratégias e prioridades (Dirigentes, 1981).

\section{Consideraçóes finais}

Samek publicou em 1999 um texto cujo título é Por uma Integração não-subordinada a Curitiba. Defendia assim, há quase duas décadas, a necessidade de se acelerar a integração das escalas do município e da regiáo metropolitana. Acreditava que haviam tentativas, entretanto, náo ficava claro como isso ocorreria, mas afirmava que não poderia ser subordinada a Curitiba, respeitando a autonomia, particularidades e potencialidades dos demais municípios. Para o autor, o modelo curitibano estava esgotado, não sendo mais referência para a RMC. Suas bases técnicas funcionalistas não se adequavam mais, tendo se mostrado excludente e criador de problemas para o próprio município e para seus vizinhos.

Confirma assim o afirmado por Hailais (2012), para quem Curitiba não foi capaz de integrar suas periferias, cada vez maiores, em um planejamento regional coerente. $\mathrm{O}$ resultado foi que as intervençóes urbanísticas mais conhecidas da cidade, como parques, ruas para pedestres, preservação histórica não se tornaram acessível para milhares de residentes metropolitanos (especialmente os mais pobres).

Reafirmam o apontado por outros autores que o método de planejamento realizado se concentra na cidade formal, deixando os que estão fora dessas áreas sem escolhas, a não ser se estabelecer em locais ilegais e desconfortáveis. O discurso sobre Curitiba de forma deliberada deixa de fora certos aspectos, e contribui para construir uma imagem da cidade que consegue resolver todos seus problemas por meio da atividade de planejar.

Somekh (2010, p. 11) afirma que no Brasil "planos e leis foram aprovados e realizados, mas quase sempre em confronto com os ditames do mercado, fenômeno que produziu um espaço urbano que parece não obedecer a regras claras". Isto fica claro quando se observa a açáo planejadora da COMEC e a pretensa flexibilidade das açóes do Ippuc, o qual, deixou de seguir as regras dos planos e agiu de acordo com outros interesses. As informaçóes expostas demonstram que a intensa divulgação do modelo de planejamento urbano de Curitiba encobre o que de fato ocorreu com as periferias da metrópole e municípios que conformam sua região. A análise mostra que o significativo peso do município-polo nas diferentes dinâmicas que interagem no espaço metropolitano, possui reflexo na forma de gestão e governança do mesmo. De forma literal, ao lado da Curitiba, reconhecida pela onu como cidade-modelo em práticas sustentáveis e economia verde (Curitiba, 2012), existem outras cidades que, à margem do progresso e enriquecimento vividos pela metrópole a partir dos anos 1970, possuem estatísticas sociais e ambientais preocupantes, o que leva, a despeito do reconhecimento internacional, a regiáo de Curitiba ser apontada como uma das mais desiguais do planeta (UN HABITAT, 2012). 


\section{Referências bibliográficas}

Arazaki, E. (2007). Centralidade de Curitiba: cenário metropolitano do desenvolvimento econômico local. Dissertação (Mestrado em Gestão Urbana), Pontifícia Universidade Católica do Paraná, Curitiba, Brasil.

Brandão, C. A. (2008). Impactos em Territórios: escalas de abordagem e açôes pelo desenvolvimento. Organizaçôes \& Sociedade, 15(45), 145-157. https://portalseer.ufba. br/index.php/revistaoes/article/view/10955

Brandão, C. A., Costa, E. J. M., \& Alves, M. A. S. (2004). Construir o espaço supra-local de articulação sócio-produtiva e das estratégias de desenvolvimento. Belo Horizonte: Centro de Desenvolvimento e Planejamento Regional (CEDeplar)/Universidade Federal de Minas Gerais (UfMG).

Carmo, J. C. B. (2018). A Serra Pelada do Urbanismo: planejando a Regiäo Metropolitana da Cidade Modelo (Curitiba e Regiáo 1961-2015). Tese (Doutorado em Arquitetura e Urbanismo), Universidade de São Paulo, São Carlos, Brasil.

Coordenação da Região Metropolitana de Curitiba (сомec). (2006). Plano de Desenvolvimento Integrado da RMC. Curitiba: comec, Secretaria de Desenvolvimento Urbano (sEDU).

Coordenação da Região Metropolitana de Curitiba (COMEC). (2017, outubro 9) Coordenação da RMC. http://www.comec.pr.gov.br

Curitiba (Prefeitura). (2012, junho 22) Secretário-geral da ONU afirma que Curitiba é modelo global. https://www.curitiba.pr.gov.br/noticias/secretario-geral-da-onu-afirma-quecuritiba-e-modelo-global/27159

Dirigentes (das Regiôes Metropolitanas). (1981). Bases para reformulação das regiốes metropolitanas. Revista de Administração Pública, 15(4), 76-88. http://bibliotecadigital. fgv.br/ojs/index.php/rap/article/view/11556

Faraco, J. L (2002). Planejamento Urbano no Paraná: a experiência de Curitiba. Tese (Doutorado em Arquitetura e Urbanismo), fau, Universidade de São Paulo, São Paulo, Brasil.

Ferrari, C. (1979). Curso de Planejamento Municipal Integrado. São Paulo: Livraria Pioneira, 2a Edição.

Firkowski, O. L. C. F. \& Casares, M. (2014). Metrópoles regionais: revisitando o conceito na perspectiva comparada Brasil-Argentina. Anais do VI Congreso Iberoamericano de Estudios Territoriales y Ambientales. São Paulo.

Godoy, J. (2012). A Expansão urbana e a reorganização da área metropolitana: o caso de São José dos Pinhais no contexto da Região Metropolitana de Curitiba. Dissertação (Mestrado em Urbanismo, História e Arquitetura da Cidade), Universidade Federal de Santa Catarina, Florianópolis, Brasil.

Hailais, F. (2012, Jun 6). Has South America's most sustainable city lost its edge? City Lab. https://www.citylab.com/transportation/2012/06/has-south-americas-mostsustainable-city-lost-its-edge/2195/

Harvey, D. (2006). Do administrativismo ao empreendedorismo: a transformaçáo da governança urbana no capitalismo tardio. In D. Harvey, A produçáo capitalista do espaço (2, pp. 163-190). São Paulo: Annablume. 
Instituto Brasileiro de Geografia e Estatística (IBGE). (2010, março 1). Censo demográfico de 2010. Rio de Janeiro, IBGE. http://censo2010.ibge.gov.br/

Instituto Brasileiro de Geografia e Estatística (IBGE). (2014, abril 14) Regiōes de Influência das Cidades, 2007. http://www.ibge.gov.br/home/geociencias/geografia/regic.shtm

Instituto Brasileiro de Geografia e Estatística (IBGE). (2016, outubro 18). Projeção da população do Brasil e das Unidades da Federação. https://ww2.ibge.gov.br/apps/populacao/ projecao/

Instituto Paranaense de Desenvolvimento Econômico e Social (IPardes). (2004). Dinâmica recente da Economia e transformaçóes na configuração espacial da Regiāo Metropolitana de Curitiba. Curitiba: IPARDES.

Klink, J. (2010). Reestruturação, competição e neolocalismo: um olhar crítico sobre produção do espaço na grande Curitiba. Revista Paranaense de Desenvolvimento, 119, 17-40. http://dx.doi.org/10.4067/S0718-34022008000100002

Lencioni, S. (2011). Referências analíticas para a discussão da metamorfose metropolitana contemporânea. Em S. Lencioni, S. Vidal-Koppmann, R. Hidalgo, \& P. C. X. Pereira (orgs.), Transformaçôes sócio-territoriais nas metrópoles de Buenos Aires, São Paulo e Santiago (pp. 51-64). São Paulo: Paim.

Moura, R. (2009). O espaço metropolitano de Curitiba e a inserção do Paraná na divisão social do trabalho. Em R. Moura \& O. L. C. F. Firkowski (orgs.), Dinâmicas intrametropolitanas e produção do espaço na Regiāo Metropolitana de Curitiba (pp. 131156). Rio de Janeiro: Letra Capital, Observatório das Metrópoles / Observatório de Políticas Públicas do Paraná.

Moura, R. (2014, abril 11). Curitiba: construção e desconstrução de um mito. http:// terradedireitos.org.br/2014/04/11/artigo-curitiba- construcao-e-desconstrucao-deum-mito-de-rosa-moura/

Moura, R. \& Rodrigues, A. L. (2009). Como andam Curitiba e Maringá. Rio de Janeiro: Letra Capital: Observatório das Metrópoles.

Nojima, D., Moura, R., \& Silva, S. T. (2009). Dinâmica recente da economia e transformaçóes na configuração espacial da Região Metropolitana de Curitiba. Em R. Moura \& O. L. C. F. Firkowski (orgs.), Dinâmicas intrametropolitanas e produçâo do espaço na Região Metropolitana de Curitiba (pp. 175-210). Rio de Janeiro, Letra Capital, Observatório das Metrópoles / Observatório de Políticas Públicas do Paraná.

Ojima, R. (2007). Análise comparativa da dispersão urbana nas aglomeraçōes urbanas brasileiras: elementos teoricos e metodologicos para o planejamento urbano e ambiental. Tese (Doutorado em Demografia), Instituto de Filosofia e Ciências Humanas (IFCH), Universidade Estadual de Campinas, Campinas, Brasil.

Pilotto, A.S. (2010). Área metropolitana de Curitiba. Um estudo a partir do espaço intraurbano. Dissertação (Mestrado em Planejamento Urbano Regional) - Faculdade de Arquitetura e Urbanismo (fau), Universidade de São Paulo, São Paulo, Brasil.

Programa das Nações Unidas para o Desenvolvimento (PNUD). (2013). Atlas do Desenvolvimento Humano nas Regiöes Metropolitanas Brasileiras. ONU, Brasília.

Rolnik, R. (2006, agosto 28). A construçâo de uma política fundiária e de planejamento urbano para o pais: avanços e desafios. http://ipea.gov.br/agencia/images/stories/PDFs/ politicas_sociais/ensaio1_raquel12.pdf

Samek, J. (1999). Curitiba: entre o mito e a realidade. Curitiba: Fotolaser. 
Somekh, N. (2010). Apresentação. In F. Ascher, F. Os novos princípios do urbanismo. Coleção RG bolso, (volume 4). São Paulo: Romano Guerra.

un-habitat. (2012). The state of Latin American and Caribbean cities 2012. Towards a new urban transition. https://www.alnap.org/help-library/the-state-of-latin-american-andcaribbean-cities-towards-a-new-urban-transition

\section{Entrevistas}

Akel, O. (2015, abril 22). Entrevista. Entrevistador: J. C. B. do Carmo. Curitiba: arquivo de áudio.

Castro Neto, V. F. (2015, agosto 15). Entrevista. Entrevistador: J. C. B. do Carmo. Curitiba: arquivo digital. 